P-ISSN: 2615-1723

E-ISSN: 2615-1766

Oktober 2019
Jurnal Riset Pendidikan Dasar

02 (2), (2019) 116-121

Submitted: Juli, Accepted Agustus, Published: Oktober

\title{
Pengaruh Penerapan Model Pembelajaran ARIAS Terhadap Hasil BelajaR IPS Siswa Kelas IV SD Inpres Mariso II Kecamatan Mariso Kota Makassar
}

\author{
Syarifah Aeni Rahman \\ ${ }^{1}$ Prodi Pendidikan Guru Sekolah Dasar, Fakultas Keguruan dan Ilmu Pendidikan, \\ Universitas Muhammadiyah Makassar, Indonesia \\ Korespondensi. E-mail: syarifah.aeni@unismuh.ac.id
}

\begin{abstract}
Abstrak
Penelitian ini bertujuan untuk mengetahui penerapan model ARIAS di kelas IV serta mengetahui perbedaan hasil belajar antara kelompok eksperimen yang menggunakan model ARIAS dan kelompok kontrol menggunakan metode konvensional matapelajaran IPS di kelas IV diSD Inpres Mariso II. Jenis Penelitian ini adalah Penelitian ini menggunakan penelitian eksperimen dengan desain Quasi Eksperimental Research. Teknik pengumpulan data melalui teknik observasi, tes dan dokumentasi. Hasil penelitian menunjukkan bahwa penerapan model pembelajaran ARIAS yaitu mengaktifkan siswa karena serangkaian langkah-langkah pembelajaran ini betul-betul melibatkan pengalaman nyata siswa, kepuasan karena dalam pembelajaran diberikan penguatan serta rasa percaya diri pada siswa. Selain itu,terdapat perbedaan yang signifikan antara hasil belajar kelompok eksperimen menggunakan model ARIASdan hasil belajar kelompok kontrol yang menggunakan metode konvensional, dimana hasil belajar kelompok eksperimen jauh lebih tinggi.
\end{abstract}

Kata Kunci: Model Pembelajaran ARIAS, Hasil belajar, IPS

\section{The Effect of ARIAS Learning Model Implementation on Social Studies Learning Outcomes of IV Grade Students of SD Inpres Mariso II, Mariso District, Makassar City}

\begin{abstract}
This study discusses the application of the ARIAS model in class IV as well as knowing the learning outcomes between the experimental group using the ARIAS model and the control group using conventional methods of social studies subjects in class IV at the Inpres Mariso II SD. This type of research is this research uses research with Quasi Experimental Research design. Data collection techniques through observation, testing and documentation. The results showed that the application of the ARIAS learning model that activates students because of taking these learning steps truly addresses students' real experiences, satisfaction because learning is given reinforcement and self-confidence in students. In addition, there are significant differences between the experimental group learning outcomes using the ARIAS model and the control group learning outcomes using conventional methods, where the experimental group learning outcomes are much higher.
\end{abstract}

Keywords: ARIAS Learning Model, Learning Outcomes, Social Studies

Copyright C2019, JRPD, ISSN 2615 - 1723 (Print), ISSN 2615 - 1766 (Online) 


\section{Jurnal Riset Pendidikan Dasar, 02 (2), Oktober 2019 (116-121)}

Syarifah Aeni Rahman

\section{PENDAHULUAN}

Pendidikan merupakan sarana penting untuk meningkatkan kualitas sumber daya manusia (SDM) dalam menjamin sebuah kemajuan suatu bangsa dan negara. Peningkatan kualitas sumber daya manusia dapat direalisasikan dalam menghadapi persaingan global sekarang ini.Pendidikan merupakan hal penting dalam kehidupan manusia, secara umum pendidikan diartikan sebagai pengajaran yang di selenggarakan oleh sekolah sebagai lembaga pendidikan formal. Pendidikan mempunyai arti luas, pendidikan dapat dimaknai sebagai proses

mengubah tingkah laku anak agar menjadi manusia dewasa yang mampu hidup mandiri dan sebagai anggota masyarakat dalam lingkungan sekitar dimana individu itu berada. Pendidikan tidak hanya mencakup pengembangan intelektualitas saja, akan tetapi lebih ditekankan pada proses pembinaan kepribadian anak didik secara menyeluruh sehingga anak menjadi lebih dewasa.

Peserta didik sebagai subjek pendidikan, dituntut supaya aktif dalam belajar mencari informasi dan mengeksplorasi sendiri atau secara berkelompok. Guru hanya berperan sebagai fasilitator dan pembimbing kearah pengoptimalan pencapaian ilmu pengetahuan yang dipelajari. Diterapkan dalam proses pembelajaran peserta didik dalam hal ini siswa mau dan mampu mengemukakan pendapat sesuai dengan apa yang telah dipahami,berinteraksi secara positif antara siswa dengan siswa dan guru apabila ada kesulitan. Namun dalam implementasi materi, pembelajaran IPS lebih banyak menekankan aspek pengetahuan yang berpusat pada guru, mengarahkan bahan berupa informasi yang kurang mengembangkan aspek berpikir nilai serta hanya membentuk budaya menghafal bukan berpikir kritis. Dalam proses pembelajaran masih sering ditemui adanya kecenderungan meminimalkan keterlibatan siswa. Dominasi guru dalam proses pembelajaran menyebabkan kecenderungan siswa lebih bersifat pasif sehingga mereka lebih banyak menunggu sajian guru daripada mencari dan menemukan sendiri pengetahuan, keterampilan atau sikap yang mereka butuhkan.

Sejalan dengan hal tesebut di atas, kondisi pembelajaran IPS terjadi pula di kelas IV SD Inpres Mariso II Kecamatan Mariso Kota Makassar. Berdasarkan observasi awal yang dilakukan oleh peneliti, ditemukan permasalahan yakni rendahnya hasil belajar IPS siswa yakni 68,67 yang belum mencapai standar ketuntasan minimal yang ditetapkan oleh sekolah yakni 70. Dari rendahnya hasil belajar tersebut, permasalahan di atas berasal dari dua aspek yaitu aspek guru dan siswa. Dari aspek guru, antara lain: (1) Pembelajaran yang dilakukan oleh guru masih menggunakan pendekatan konvensional seperti paduan ceramah dan tanya jawab dan pemberian tugas. Pendekatan konfensional yang digunakan guru masih kurang merangsang siswa untuk belajar giat, (2) Dominasi guru dalam pembelajaran, (3) Guru lebih menekankan pada aspek pengetahuan saja belum menyentuh pada sikap dan keterampilan. Sedangkan dari aspek siswa: (1) Siswa masih ragu dalam mengungkapkan pendapat ataupun mengajukan pertanyaan mengenai materi pembelajaran yang belum dipahami, (2) Siswa merasa bosan untuk belajar IPS karena selalu cenderung menghafal, (3) Kerja sama dalam kelompok masih kurang.

Berdasarkan realita di atas sehingga memicu ketuntasan belajar dalam kategori rendah yang tercermin pula dalam prestasi belajar karena penerapannya berpusat didalam kelas saja.Oleh karena itu, peneliti memilih model ARIAS ini karena pada hakikatnya belajar merupakan interaksi antara individu dengan lingkungannya. Siswa secara aktif dapat terlibat dalam proses pembelajaran, sehingga pembelajaran IPS menarik bagi siswa untuk dipelajari. Berdasarkan landasan 


\section{Jurnal Riset Pendidikan Dasar, 02 (2), Oktober 2019 (116-121)}

Syarifah Aeni Rahman

penelitian inilah, peneliti ingin mengetahui lebih jauh tentang "Pengaruh Penerapan Model ARIAS Terhadap Hasil Belajar IPS di SD Inpres Mariso II Kecamatan Mariso Kota Makassar." Oleh sebab itu, dari sinilah penulis tertarik untuk mengadakan penelitian di sekolah tersebut.

\section{METODE}

Metode penelitian merupakan prosedur dan teknik penelitian. Antara satu penelitian dengan penelitian yang lain, prosedur dan tekniknya akan berbeda. Kalau tidak berbeda, berarti penelitian itu hanya mengulang penelitian yang sudah ada sebelumnya. Tapi bukan berarti harus berbeda semuanya. Untuk penelitian sosial misalnya, populasi penelitian mungkin saja sama, tapi teknik samplingnya berbeda, teknik pengumpulan datanya berbeda, analisis datanya berbeda, dan lain-lain.

Mohon metode penelitian diuraikan dengan jelas, tidak hanya mengopi dari penelitian lain. Bagian ini bisa dibagi menjadi beberapa sub bab, tetapi tidak perlu mencantumkan penomorannya. Metode ditulis dengan huruf Calisto MT - 11 dan line space 1,15 . Panjang bagian ini $10-15 \%$ dari total panjang artikel.

\section{HASIL DAN PEMBAHASAN}

Model pembelajaran adalah tahap-tahap atau rangakaian kegiatan yang akan dilaksankan dalam proses pembelajaran. Salah satu model pembelajaran yang akan digunakan adalah model pembelajaran ARIAS. Seperti yang telah dijelaskan model pembelajaran ARIAS terdiri dari lima komponen (Assurance, Relevance, Interest, Assessment, Satisfaction). Kelima komponen tersebut merupakan satu kesatuan yang diperlukan dalam kegiatan pembelajaran. Menurut Muliana (2012) Penerapan model Pembelajaran ARIAS pada pembelajaran IPS, adapun langkah-langkah model pembelajaran ARIAS antara lain adalah sebagai berikut:
1)Guru membangkitkan dan menjaga minat/perhatian siswa dengan menjelaskan materi yang berhubungan dengan karangan bebas menggunakan bahasa yang jelas.

2)Menyebutkan tema/ pokok pembahasan yang ada hubungannya dengan kehidupan nyata yang dimiliki siswa.

3) Memberikan kesempatan kepada siswa untuk menanyakan materi yang belum dipahami.

4) Memberikan tugas berupa pengamatan di luar kelas dan memberikan LKM untuk mengerjakan tugas dari masing-masing kelompok.

5) Setelah selesai mengerjakan LKM, beberapa siswa diminta untuk membacakan hasil kerjanya.

6) Memberi penguatan kepada siswa yang telah menampilkankeberhasilannya secara verbal dan non verbal dengan mengucapkan kata bagus sambil tersenyum dan mengacungkan jempol kepada siswa.

7) Membuat kesimpulan.

Hasil pre test kelompok kontrol yang menggunakan metode pembelajaran yang biasa digunakan guru dengan jumlah subjek adalah 20 siswa. Berdasarkan tabel di atas, hasil pre test kelompok kontrol diperoleh modus adalah 63,33 . Adapun mean pre test kelompok kontrol adalah 58,33.

Hasil post test kelompok eksperimen yang mendapat perlakuan, yaitu dengan menggunakan model ARIAS dengan jumlah subjek adalah 20 siswa. Hasil post test kelompok eksperimen diperoleh modus adalah 73,33 Adapun mean post test kelompok eksperimen adalah 72,50 .

Uji normalitas digunakan untuk mengetahui apakah data yang diperoleh dari masing-masing variabel berdistribusi normal atau tidak. Perhitungan uji normalitas menggunakan rumus Kolmogorov-Smirnov dengan taraf signifikan 5\%. Seluruh proses perhitungan dilakukan dengan bantuan komputer program SPSS Versi 21.0 for windows. Uji normalitas ini dilakukan 


\section{Jurnal Riset Pendidikan Dasar, 02 (2), Oktober 2019 (116-121)}

Syarifah Aeni Rahman

terhadap skor pre test dan post test siswa pada mata pelajaran IPS, baik kelompok eksperimen maupun kelompok kontrol. Kriteria yang digunakan adalah jika harga $\mathrm{p}>0,05$ maka distribusi frekuensi tersebut normal, sebaliknya jika harga $\mathrm{p}<0,05$ maka distribusi frekuensi tidak normal

Berdasarkan data tersebut, dapat diperoleh hasil bahwa nilai KolomogrovSmirnov Z pada pre test kelompok eksperimen 0,926 dengan Sig 0,358 dan nilai KolomogrovSmirnov $Z$ pada post test kelompok eksperimen 0,699 dengan Sig 0,712. Nilai Kolomogrov-Smirnov $\mathrm{Z}$ pada pre test kelompok kontrol 0,744 dengan Sig 0,637 dan nilai Kolomogrov-Smirnov $\mathrm{Z}$ pada post test kelompok kontrol 0,703 dengan Sig 0,706. Dari data tersebut dapat dilihat bahwa Asymp Sig (2-tailed) distribusi data yang diperoleh lebih besar dari harga alpha 0,05. Dapat disimpulkan bahwa Asymp Sig (2-tailed) distribusi data pre test dan post test pada masing-masing variabel normal sehingga dapat digunakan untuk uji statistik parametrik.

Uji homogenitas digunakan untuk mengetahui apakah sampel yang diambil memiliki varian yang sama atau tidak menunjukkan perbedaan yang signifikan satu sama lain. Uji homogenitas dalam penelitian ini menggunakan uji levene test. Seluruh proses perhitungan dilakukan dengan bantuan komputer program SPSS versi 21.0 for windows. Kriteria yang digunakan yaitu dari data hasil penelitian yang dikatakan homogen apabila hasil levene test lebih besar dari harga alpha yaitu 0,05 .

Berdasarkan data tersebut, dapat diperoleh hasil bahwa nilai Levene pada pre test kelompok eksperimen-kontrol 0,019 dengan Sig 0,891 dan nilai Levene pada post test kelompok eksperimen-kontrol 2,581 dengan Sig 0,161. Nilai Levene pada pre testpost test kelompok eksperimen 0,583 dengan Sig 0,450 dan nilai Levene pada pre test-post test kelompok kontrol 0,702 dengan Sig 0,407. Dari data tersebut dapat dilihat bahwa Asymp Sig (2-tailed) distribusi data yang diperoleh lebih besar dari harga alpha 0,05. Dapat disimpulkan bahwa Asymp Sig (2- tailed) distribusi data pre test dan post test pada kelompok eksperimen kontrol homogen, distribusi data pre test dan post test pada kelompok eksperimen homogen, dan distribusi data pre test dan post test kelompok kontrol homogen. Dengan demikian penelitian ini layak untuk dilanjutkan.

Uji hipotesis dilakukan setelah semua data dari hasil penelitian terkumpul. Tujuan dari uji Paired T-test untuk menguji apakah model ARIAS memiliki kinerja yang lebih baik terhadap peningkatan Hasil belajar IPS siswa kelas IV SD Inpres Mariso II Kecamatan Mariso Kota Makassar dibanding metode pembelajaran yang digunakan guru selama ini.Berdasarkan data tersebut, hasil analisis uji Paired T-test menunjukkan bahwa nilai $t$ hitung dari pre test-post test kelompok eksperimen sebesar 13,784 dan t hitung dari pre test-post test kelompok kontrol sebesar 5,080. Dari data tersebut terlihat nilai t hitung $>\mathrm{t}$ tabel pada kedua kelompok, namun $\mathrm{t}$ hitung pada kelompok eksperimen lebih besar dari t hitung kelompok kontrol sehingga $\mathrm{Ha}$ diterima dan Ho ditolak. Artinya model ARIAS memiliki kinerja yang lebih baik terhadap peningkatan Hasil belajar IPS siswa kelas IV SD Inpres Mariso II dibanding metode pembelajaran konvensional yang digunakan guru selama ini. Jadi dapat disimpulkan bahwa terdapat kinerja yang lebih baik pada kelompok eksperimen yang menggunakan model ARIAS dibandingkan dengan kelompok kontrol yang menggunakan metode pembelajaran yang biasa digunakan guru selama ini.

Berdasarkan hasil analisis data yang telah dikemukakan di atas, maka dapatlah dipaparkan bahwa model ARIAS ini merupakan salah satu model pembelajaran dapat digunakan agar siswa lebih dapat memahami materi pada saat proses pembelajaran berlangsung. Penelitian ini dapat diperkuat lagi dengan teori belajar yang

Copyright C2019, JRPD, ISSN 2615 - 1723 (Print), ISSN 2615 - 1766 (Online) 


\section{Jurnal Riset Pendidikan Dasar, 02 (2), Oktober 2019 (116-121)}

Syarifah Aeni Rahman

dijabarkan oleh Sanjaya (2015) bahwa proses belajar terjadi berkat siswa memperoleh sesuatu yang ada di lingkungan sekitar.

Menurut Ahmadi (2011) mengemukakan bahwa model ARIAS adalah modifikasi model dalam kegiatan pembelajaran untuk menanamkan rasa yakin/percaya pada siswa. Kegiatan pembelajaran ada relevansinya dengan kehidupan siswa, berusaha menarik dan memelihara minat/perhatian. Kemudian diadakan evaluasi dan menumbuhkan rasa bangga pada siswa dengan memberikan penguatan (reinforcement). Pelaksanaan kegiatan belajar yang mengandung lima komponen yaitu: assurance (percaya diri), relevance (relevansi), interest (minat), assessment, yaitu yang berhubungan dengan evaluasi terhadap siswa dan satisfaction (kepuasan/bangga).

Penelitian ini membuktikan bahwa terdapat perbedaan hasil belajar siswa yang menggunakan model ARIAS dengan metode konvensional dalam proses pembelajaran. Perbedaan tersebut ditunjukan oleh perbandingan rata-rata skor hasil belajar pada setiap item test antara kelas eksperimen dan kelas kontrol. Pada penelitian untuk kelas eksperimen yang menggunakan model ARIAS hasil belajar siswa lebih tinggi. Dibanding pada kelas kontrol yang tidak menggunakan metode konvensional dimana hasil belajar siswa rendah. Kelebihan yang dimiliki oleh model ARIAS menurut Muliana (2012) diantaranya bahwa model ini dapat membuktikan mengaktifkan siswa karena serangkaian langkah-langkah pembelajaran ini betul-betul melibatkan pengalaman nyata siswa,

model pembelajaran ini juga dapat menimbulkan kepuasan tersendiri bagi siswa karena diakhir pembelajaran akan ada pemberian penguatan atas hasil kerja/tugas yang telah diberikan, serta menanamkan rasa percaya diri dalam diri siswa.

Dengan demikian dapat dikatakan bahwa hipotesis yang telah dirumuskan yaitu "Terdapat perbedaan hasil belajar siswa yang menggunakan model ARIAS dengan metode konvensional" dapat diterima.

Hasil pengujian di atas memberikan gambaran bahwa pembelajaran yang menggunakan model ARIAS mendapatkan hasil yang baik dibandingkan dengan metode konvensional atau yang menggunakan metode ceramah. Dalam artian bahwa model ARIAS ini dapat digunakan dalam proses pembelajaran yang sesuai dengan materi pokok bahasan di sekolah karena tingkat pencapaian indikator kelas eksperimen lebih tinggi dibandingkan dengan pencapaian indikator untuk kelas kontrol.

\section{SIMPULAN}

Berdasarkan hasil temuan dalam penelitian ini maka dapat disimpulkan sebagai berikut :

1. Penerapan model pembelajaran ARIAS yaitu mengaktifkan siswa karena serangkaian langkah-langkah pembelajaran ini betul-betul melibatkan pengalaman nyata siswa, kepuasan karena dalam pembelajaran diberikan penguatan serta rasa percaya diri pada siswa.

2. Terdapat perbedaan yang signifikan antara hasil belajar kelompok eksperimen menggunakan model ARIASdan hasil belajar kelompok kontrol yang menggunakan metode konvensional, dimana hasil belajar kelompok eksperimen jauh lebih tinggi.

\section{DAFTAR PUSTAKA}

Ahmadi. (2011). Strategi Pembelajaran Sekolah Terpadu. Jakarta: PT. Prestasi Pustaka.

Bundu, P. (2010). Aplikasi Keterampilan Proses Dalam Pembelajaran di Sekolah Dasar. Makassar: Samudra Alif-Mim.

Erna,D. (2010). Profesionalisme Guru dalam Mengajar. Bandung: Alfabeta.

Muliana. (2012). Peningkatan Hasil Belajar Muriddalam Mata Pelajaran IPA Melalui 
Model Pembelajaran Assurance, Relevance, Interest,Assessment Satisfaction (ARIAS) Di Kelas IV SD Inpres Tidung Kecamatan Rappocini Kota Makassar. Skripsi. Makassar: Universitas Negeri Makassar.

Sanjaya,W.(2010).Strategi Pembelajaran. Jakarta:

Kencana Prenada Media Group.

Santrock, J.W. (2011). Psikologi Pendidikan. Jakarta: Kencana Prenada Media Grup.

Sapriya. (2009). Pendidikan IPS: Konsep \&

Pembelajaran. Bandung: Remaja

Rosdakarya

Sugiono.(2016).MetodePenelitianPendidikanPendek atanKuantitatif,Kualitatif,R\&D.Bandung: Alfabeta.

Suprijono,A. (2014). Cooperative Learning. Yogyakarta: PustakaBelajar.

Sanjaya,W. (2015). StrategiPembelajaran. Jakarta: Kencana Prenada Media Group. 